\title{
La fin de la cotisation syndicale obligatoire au Brésil
}

\section{Juliano Barra}

\section{(2) OpenEdition}

1 Journals

Édition électronique

URL : https://journals.openedition.org/rdctss/1676

DOI : $10.4000 /$ rdctss. 1676

ISSN : 2262-9815

Éditeur

Centre de droit comparé du travail et de la sécurité sociale

\section{Édition imprimée}

Date de publication : 1 avril 2019

Pagination : 180-181

ISSN : 2117-4350

\section{Référence électronique}

Juliano Barra, « La fin de la cotisation syndicale obligatoire au Brésil », Revue de droit comparé du travail et de la sécurité sociale [En ligne], 1 | 2019, mis en ligne le 01 novembre 2021, consulté le 13 novembre 2021. URL : http://journals.openedition.org/rdctss/1676 ; DOI : https://doi.org/10.4000/rdctss.1676

\section{c) (i) $\odot($}

Revue de droit comparé du travail et de la sécurité sociale est mise à disposition selon les termes de la Licence Creative Commons Attribution - Pas d'Utilisation Commerciale - Pas de Modification 4.0 International. 


\title{
JULIANO BARRA
}

\author{
UnIVERSITÉ PARIS 1 PANTHÉON-SORBONNE
}

\section{LA FIN DE LA COTISATION SYNDICALE OBLIGATOIRE AU BRÉSIL}

Entrée en vigueur depuis novembre 2017, la loi n 13467 du 13 juillet 2017 a modifié une centaine d'articles de l'Acte de Consolidation des Lois du Travail - CLT brésilienne. Considérée comme la plus importante réforme des derniers temps en matière de droit du travail, elle a modifié les articles 545, 578, 579, 582, 583, 587 et 602 de la CLT pour remplacer le régime des cotisations syndicales obligatoires par un régime facultatif. La Cour suprême (Supremo Tribunal Federal - STF) s'est prononcée le 29 juin 2018 sur la constitutionnalité de ces modifications (I). Les syndicats brésiliens devront surmonter une crise de représentativité (II).

\section{I - LA FIN DE LA COTISATION SYNDICALE OBLIGATOIRE}

L'article 578 de la CLT prévoyait que les montants prélevés en faveur des syndicats (salariés et employeurs) seraient nommés «impôt syndical ». L'article 580, pour sa part, énonçait que l'«impôt syndical» serait versé de façon obligatoire une fois par an et correspondrait (a) au montant de la rémunération d'une journée de travail, pour les salariés et (b) selon un montant fixe, serait proportionnel au capital social de l'entreprise, pour les employeurs. Le Brésil figurait ainsi parmi les seuls pays où la cotisation syndicale était obligatoire pour tous les salariés et employeurs, indépendamment de l'affiliation ou non aux syndicats ou organisations patronales. La loi du 13 juillet 2017 a mis un terme à cette idiosyncrasie de la législation travailliste brésilienne. La nouvelle rédaction de l'article 578 de la CLT dispose que ces cotisations seront dues aux syndicats, à condition que les salariés y aient consenti, excluant par là tout caractère obligatoire. Saisie par dix-neuf «actions directes d'inconstitutionnalité " (ADI 5794) et une "action directe de constitutionnalité " (ADC 55), la Cour Suprême brésilienne, par six votes contre trois, a jugé conforme à la Constitution les modifications concernant le nouveau régime des cotisations syndicales. La position majoritaire a consacré les éléments suivants pour déclarer la constitutionnalité :

- La violation du principe de l'égalité fiscale n'a pas été prouvée considérant que le critère est homogène et égalitaire, en exigeant l'autorisation préalable du travailleur pour le prélèvement de la contribution syndicale.

- Comme il ne s'agit pas d'un impôt, les règles relatives à la limitation du pouvoir d'imposition sont exclues.

- L'absence de dispositions dans la Constitution visant à autoriser le prélèvement obligatoire de cotisations syndicales.

- La cotisation syndicale obligatoire figure parmi les motifs de l'explosion du nombre de syndicats au Brésil, laissant le soin au législateur de corriger cette distorsion.

- La cotisation syndicale obligatoire se heurte à la disposition constitutionnelle sur la liberté d'association et d'expression.

Il importe de remarquer que le législateur brésilien, conformément à la Constitution, n'a pas interdit d'autres formes de financement des syndicats, comme par exemple des cotisations prévues par les conventions collectives et votées par une assemblée, conformément à l'article 513-E de la CLT. Les cotisations obligatoires étaient un héritage d'une intervention étatique archaïque qui a eu pour conséquence une forte crise de représentativité des syndicats brésiliens. 


\section{II - DÉFICIT DE REPRÉSENTATIVITÉ DES SYNDICATS BRÉSILIENS}

Si la Constitution de 1988 a rompu avec tout interventionnisme des pouvoirs publics au sein des syndicats, en abrogeant ces aspects prévus par la CLT, elle maintient tout de même la politique du syndicat unique par catégorie professionnelle sur une base territoriale, et, parallèlement, n'interdisait pas la cotisation annuelle obligatoire pour salariés et employeurs, indépendamment de l'affiliation ou non aux syndicats1. Les spécialistes ont observé que ces dispositions avaient été autrefois nécessaires dans un Brésil agricole, avec une faible densité de population et peu de syndicats. Le contexte économique et social du pays ayant évolué, ce régime juridique, empêchant toute concurrence entre les syndicats, ne se justifiait plus. Si le taux de syndicalisation moyen en Europe est d'environ $23 \%$, en France $11 \%$, en Lituanie $10 \%$, en Suède et Finlande $70 \%$, au Brésil ce taux est de $12 \%$ pour 17200 syndicats (en 2017). Comment peut-on justifier dans un pays dont le régime est celui de l'unicité syndicale (pas de concurrence entre syndicats) l'existence de presque vingt mille syndicats? Les cotisations syndicales obligatoires sont une partie de la réponse et leur interdiction par le législateur peut créer de nouvelles opportunités pour de vrais syndicats.Le déficit de représentativité des syndicats brésiliens rappelle les défis que le mouvement syndical mondial est en train de relever. Le rapport de I'OIT sur "L'avenir du travail » illustre bien ce moment: «De quelle manière les États, les employeurs et les travailleurs vont-ils collaborer pour concevoir et mettre en œuvre des institutions et des outils visant la gouvernance du travail à l'avenir? Quel sera le rôle joué par les formes privées et volontaires d'autoréglementation? Commentles employeurs et les travailleurs s'organiseront collectivement, et comment leurs formes d'organisation collective vont garantir une représentation légitime dans les processus de collaboration? Comment la gouvernance du travail pourrait être renforcée au niveau transnational ? Faudrait-il créer de nouvelles institutions et instruments dans ce domaine? " ${ }^{2}$ La fin de la cotisation syndicale obligatoire a été le premier pas en direction d'une redéfinition de ce que la société brésilienne attend des syndicats. II faut aller plus loin dans la réforme constitutionnelle afin de briser le régime d'unicité syndicale, donnant ainsi tout son sens à une ratification future de la Convention 87 de l'OIT.

1 La question syndicale brésilienne et son actuelle structure doivent impérativement faire l'objet d'un débat plus approfondi. Selon l'article $8^{\circ}$ de la Constitution Fédérale de 1988, relatif à la formation des syndicats, "La formation d'associations syndicales ou professionnelles est libre, selon les conditions suivantes: I - la loi ne peut exiger d'autorisation de l'État pour la création d'un syndicat, sauf son enregistrement auprès de l'organe compétent; l'intervention et l'interférence de la puissance publique dans l'organisation syndicale sont interdites; II - il est interdit de créer plus d'une organisation syndicale, à quelque niveau que ce soit, pour représenter une même catégorie professionnelle ou économique sur une même base territoriale; celle-ci, définie par les travailleurs et employeurs intéressés, ne peut être inférieure au territoire de la Commune; III il appartient au syndicat de défendre les intérêts collectifs ou individuels de chaque catégorie, y compris en matière juridique et administrative; IV - l'assemblée générale fixe la cotisation de chaque catégorie professionnelle considérée, qui est prélevée sur le salaire pour le financement du système confédéral de représentation syndicale sans préjudice de la contribution prévue par la loi ; V - nul ne peut être obligé à adhérer ou à maintenir son adhésion à un syndicat; VI - la participation des syndicats aux négociations collectives du travail est obligatoire; »

2 Rapport initial pour la Commission mondiale sur l'avenir du travail, Genève, Bureau international du Travail, OIT, 2017, p. 43. 